\title{
Palm oil taxes and cardiovascular disease mortality in India: economic-epidemiologic model
}

\author{
(C) $(1) \Theta$ OPEN ACCESS
}

\author{
Sanjay Basu assistant professor of medicine ${ }^{123}$, Kim S Babiarz research economist ${ }^{2}$, Shah Ebrahim \\ professor of public health ${ }^{34}$, Sukumar Vellakkal health economist ${ }^{4}$, David Stuckler senior research \\ leader $^{35}$, Jeremy D Goldhaber-Fiebert assistant professor of medicine ${ }^{2}$
}

${ }^{1}$ Prevention Research Center, and Center on Poverty and Inequality, Stanford University, Stanford, CA, USA; ${ }^{2}$ Centers for Health Policy, Primary Care and Outcomes Research, Stanford University; ${ }^{3}$ London School of Hygiene and Tropical Medicine, London, UK; ${ }^{4}$ South Asia Network for Chronic Disease, Public Health Foundation of India, Delhi, India; ${ }^{5}$ Department of Sociology, Oxford University, Oxford, UK

\begin{abstract}
Objective To examine the potential effect of a tax on palm oil on hyperlipidemia and on mortality due to cardiovascular disease in India. Design Economic-epidemiologic model.

Modeling methods A microsimulation model of mortality due to myocardial infarction and stroke among Indian populations was constructed, incorporating nationally representative data on systolic blood pressure, total cholesterol, tobacco smoking, diabetes, and cardiovascular event history, and stratified by age, sex, and urban/rural residence. Household expenditure data were used to estimate the change in consumption of palm oil following changes in oil price and the potential substitution of alternative oils that might occur after imposition of a tax. A $20 \%$ excise tax on palm oil purchases was simulated over the period 2014-23.
\end{abstract}

Main outcome measures The model was used to project future mortality due to myocardial infarction and stroke, as well as the potential effect of a tax on food insecurity, accounting for the effect of increased food prices.

Results A $20 \%$ tax on palm oil purchases would be expected to avert approximately 363000 (95\% confidence interval 247000 to 479000$)$ deaths from myocardial infarctions and strokes over the period 2014-23 in India (1.3\% reduction in cardiovascular deaths) if people do not substitute other oils for reduced palm oil consumption. Given estimates of substitution of palm oil with other oils following a $20 \%$ price increase for palm oil, the beneficial effects of increased polyunsaturated fat consumption would be expected to enhance the projected reduction in deaths to as much as 421000 (256 000 to 586000 ). The tax would be expected to benefit men more than women and urban populations more than rural populations, given differential consumption and cardiovascular risk. In a scenario incorporating the effect of taxation on overall food expenditures, the tax may increase food insecurity by $<1 \%$, resulting in 16000 (95\% confidence interval 12000 to 22000$)$ deaths.

Conclusions Curtailing palm oil intake through taxation may modestly reduce hyperlipidemia and cardiovascular mortality, but with potential distributional consequences differentially benefiting male and urban populations, as well as affecting food security.

\section{Introduction}

Four out of five deaths from chronic disease now occur in low and middle income countries. ${ }^{1}$ India is projected to have more deaths from cardiovascular disease than any other country in the world over the next decade. ${ }^{2}$ Hyperlipidemia is a leading contributor to mortality due to cardiovascular disease. ${ }^{3}$ Given limited healthcare infrastructure in parts of India and other low and middle income countries, one approach to reducing hyperlipidemia is to reduce consumption of dietary sources of saturated fat. Consistent evidence indicates that palm oil represents a significant and increasing source of saturated fat for populations of low and middle income countries, ${ }^{4}$ that such saturated fat intake increases serum cholesterol, ${ }^{56}$ and that rises in serum cholesterol linearly increase rates of death from cardiovascular disease. ${ }^{7}$ Palm oil accounts for most of Indian vegetable oil imports and nearly $48 \%$ of domestic consumption of oil for food, ${ }^{8}$ in part because it is typically $20-30 \%$ cheaper than other oils. Globally, palm oil has now surpassed soybean oil in global consumption (fig $1 \Downarrow$ ). ${ }^{8}$ Palm oil contains approximately $49 \mathrm{~g}$ saturated fat per $100 \mathrm{~g}$ oil, as opposed to $17 \mathrm{~g}$ in peanut oil, $16 \mathrm{~g}$ in soybean oil, and $7 \mathrm{~g}$ in canola/rapeseed oil. ${ }^{10}$ Consequently, palm oil induces a larger increase in plasma concentrations of total cholesterol and low density lipoproteins. ${ }^{6}$ Palm oil consumption is strongly 
associated with higher rates of death from myocardial infarction in low and middle income countries, even after adjustment for time trends, tobacco use, and other saturated fat sources. ${ }^{4}$

Reducing palm oil intake has recently been suggested as a strategy to lower hyperlipidemia and mortality due to cardiovascular disease in low and middle income countries. ${ }^{1}$

Replacing saturated fats with polyunsaturated fats has reduced mortality due to myocardial infarction in randomized controlled trials, ${ }^{11}$ as well as at the population level in Poland and Mauritius. ${ }^{12}{ }^{13}$ Fiscal interventions such as taxes and subsidies have been suggested to reduce consumption of foods high in saturated fats, but these have been controversial. ${ }^{14}$ Fiscal interventions are delivered at the population level, making randomized controlled trials of their effect difficult; hence, mathematical models have been used to assess the potential effects of these interventions, including potential adverse consequences.

We developed a model to simulate the risk of death from myocardial infarctions and strokes in India, using nationally representative data on key risk factors including systolic blood pressure, total cholesterol, tobacco smoking, and diabetes. The model considered the potential cardiovascular health effects of a $20 \%$ excise tax on palm oil among various subpopulations in India, examining price mediated effects on consumption of both palm oil and other oils. We chose a $20 \%$ tax to be in line with other food taxes proposed to discourage unhealthy caloric intake, as well as to allow for reasonable estimation of how much a price change would affect palm oil consumption as well as substitution with other oils, given existing price fluctuations that have varied the price of palm oil by as much as $27 \%$ over the past decade. ${ }^{15}$ The model also considered potential adverse effects of the tax on food security, given the effect of taxation on overall food budgets.

\section{Methods}

The underlying structure and assumptions behind the model are described below. The table $\Downarrow$ itemizes the model's parameters and data sources. Full model equations and input data are in the web appendix. The key model assumptions are that changes in intake of saturated and polyunsaturated fat affect serum cholesterol over time on the basis of a previously validated formula $^{27}$; that estimates of own price and cross price elasticity provide an estimate of how much a palm oil tax would be expected to reduce palm oil intake and how much people deferring palm oil consumption would be expected to substitute other common oils for palm oil, in turn affecting their saturated and polyunsaturated fat intakes; and that changes in serum cholesterol are related to changes in the risk of myocardial infarction and ischemic stroke on the basis of international relative risk estimates shown in the table $\downarrow$ and appendix table 9 (which are potentially conservative underestimates of risk among South Asians ${ }^{28}$ ).

\section{Cardiovascular disease mortality model}

We used a discrete time microsimulation model to forecast deaths from myocardial infarctions and ischemic strokes among Indian residents aged 20 to 79 years in yearly time steps over a 10 year period starting in 2014 (fig $2 \Downarrow$ ). The model stratifies India's population into 24 cohorts defined by 10 year age groups (20-29 through 70-79 years), sex, and rural versus urban residence, incorporating demographic trends in population growth (appendix section 1).

In the model, each cohort contains 10000 representative people. Each person is assigned a cardiovascular disease "risk factor profile" based on data from the World Health Organization's nationally representative Study on Global Aging and Adult Health (SAGE) from 2007 to 2010 and its sister household based health surveys that have undergone extensive validation and are the best publically available, updated, population representative source of cardiovascular risk information on India (appendix tables 1-6). ${ }^{17}$ The profile comprises six established cardiovascular risk factors: systolic blood pressure, total cholesterol, tobacco smoking, diabetes, and previous history of coronary heart disease or cerebrovascular disease. Body mass index is not part of the profile because it is not a significant independent predictor of myocardial infarctions or strokes after adjustment for the other risk factors. ${ }^{23}{ }^{29}$ Each person's risk factor profile is determined by sampling from cohort specific joint probability distributions of the risk factors; the sampling is guided by a correlation matrix between the risk factors (appendix table 7). Risk factor values are updated annually to account for secular trends in risk (appendix table 8).

The relative risk of death from myocardial infarction or ischemic stroke conferred by a person's risk profile is used to calculate that person's probability of death from myocardial infarction or stroke in each year of the simulation (appendix table 9). A person's probability of death is based on the cohort specific rates of death from myocardial infarction and stroke (appendix table 10), which are calculated by using a validated algorithm that accounts for the independent effects of each risk factor and their combined effects. ${ }^{23}$ A standard competing risks algorithm estimates the probability of death from other causes (appendix tables 10 and 11). ${ }^{30} \mathrm{We}$ also externally validated the model's predictions of deaths against government estimates for myocardial infarction, stroke, and all cause mortality in India, matching these external data points to within 5\% error without any model fitting (appendix figure 1, A-C).

\section{Palm oil tax simulation}

The model projected deaths from myocardial infarctions and strokes in India over a 10 year period in the presence of a $20 \%$ palm oil tax ("tax scenario") compared with deaths without such a tax ("baseline scenario"), assuming continued linear trends in consumption (fig $1 \Downarrow$ ). The $20 \%$ rate mirrored other proposed food tax rates and was varied from $10 \%$ to $30 \%$ in sensitivity analyses. ${ }^{31}$ We used standard microeconomic demand system equations to estimate how changes in the price of palm oil affect consumption of palm oil, substitution of palm oil with other oils, and households' real expenditures on oil. ${ }^{32}$ The demand system, which estimates own price and cross price elasticities (table $\downarrow$ ), was estimated using data from the Indian National Sample Survey, a repeated annual nationally representative cross sectional household survey that collects food consumption and price data. ${ }^{33}$ Appendix section 1.4 provides the demand system equations and estimation details.

The elasticity estimates suggested that for each $1 \%$ increase in the price of palm oil, consumption of palm oil decreases by $0.71 \%$. Importantly, the demand system also captures substitution of other oils for palm oil and allows us to estimate the overall expenditure effects of the tax (expenditure elasticity). For a $1 \%$ increase in the price of palm oil, the cross elasticities suggest a $0.70 \%$ rise in rapeseed and mustard seed oil consumption and a $0.67 \%$ rise in groundnut oil consumption, but no significant increase in coconut oil consumption (table $\Downarrow$ ). Note that whereas the substituted oils increase percentage-wise by more than the percentage decrease in palm oil consumption, the actual volume increases in consumption of the substituted oils are smaller than the volume change in palm oil consumption, owing to different starting volumes consumed (more palm oil 
is consumed at baseline, hence a $0.7 \%$ change in palm oil is a larger volume than a $0.7 \%$ rise in rapeseed and mustard seed and a $0.67 \%$ rise in groundnut oil consumption). The prices also differ among oils, so that the money deferred from palm oil can be used for a correspondingly larger percentage increase in consumption of alternative oils. These elasticity estimates closely match older price elasticity estimates from India. ${ }^{34}$ In addition to these substitutions for rapeseed, mustard seed, and groundnut oils, we also accounted for the fact that the National Sample Survey data contain an aggregate "other oils" category, which contains oils that have both high saturated fat and low polyunsaturated fat content (cottonseed) and vice versa (soybean). We modeled two scenarios of potential substitutions within this "other" oils category-a pessimistic and an optimistic scenario-in which we assumed that each rupee deferred from palm oil consumption after a tax that did not already go to one of the major oils (rapeseed, mustard seed, or groundnut) would, after adjustment for price differences and change in household food expenditure, go to purchasing the next least healthy "other" oil in terms of saturated fat to polyunsaturated fat ratio (cottonseed oil, pessimistic case) or the most healthy alternative "other" oil in terms of saturated fat to polyunsaturated fat ratio (soybean oil, optimistic case).

Hence, we simulated four scenarios: a baseline case with no tax; a 20\% palm oil tax with no substitution with other oils; a $20 \%$ palm oil tax in which substitution of palm oils with other oils occurred, including a pessimistic substitution of cottonseed oil from the "other" oils category; and a 20\% palm oil tax with substitution with other oils, including an optimistic substitution of soybean oil from the "other" oils category.

\section{Effect on cholesterol and cardiovascular risk}

To estimate the relation between changes in consumption of the various oils and changes in total cholesterol, we used Keys' formula (appendix section 1.4), which relates average quantities of saturated fat and polyunsaturated fat consumed to changes in serum cholesterol. ${ }^{27}$ This approach has been validated in South Asian and other cohorts. ${ }^{27}{ }^{35}$ The saturated and polyunsaturated fat compositions of the oils came from the US Department of Agriculture's Nutrient Database for Dietary Studies, ${ }^{10}$ which were found to be consistent with the Nutritive Value of Indian Foods database (table $\Downarrow$ ). ${ }^{36}$

The microsimulation model adjusted cholesterol in the risk factor profiles on the basis of the calculation of change in serum cholesterol. Only $43 \%$ of the simulated population experienced the change, as this is the proportion of the current Indian population consuming palm oil in their homes. ${ }^{37} \mathrm{We}$ conservatively assumed that the decline in cholesterol would take place at a linear rate over five years, given the experience in Mauritius. ${ }^{13}$

\section{Potential adverse effects}

Because a palm oil excise taxation raises the price of a food item, its net effect on health and wellbeing is particularly unclear for those who are at risk of becoming food insecure. To the extent that an increase in the price of palm oil results in people either spending more of their overall budgets on food (not substituting cheaper oils) or foregoing some calories because of cost (as calorie intake is lower for most of the cheaper oils), palm oil taxes might have adverse effects on net energy consumption, food security, or both.

We calculated the added financial burden of a palm oil tax and the burden of purchasing other oils among those who switch from palm to other oils. We used the latest price data available from India (from 2010) for the various oils. ${ }^{37}$ We calculated the new equilibrium prices following a rise in demand from demand and supply functions on the basis of data from the Food and Agricultural Organization. ${ }^{26}$ As detailed in appendix section 1.5 , we estimated the change in kilocalorie consumption, taking into account the change in household expenditure (spending power) and differences in calorie content per oil. Current levels of food insecurity came from the Food and Agricultural Organization's estimates of the distribution of calorie intake in India; we shifted this distribution by the estimated change in kilocalorie consumption per capita after the palm oil tax. ${ }^{26} \mathrm{We}$ estimated, from the cumulative distribution function of this calorie distribution, the number of people who newly fall below the reported threshold for "minimum dietary energy requirement" (1780 kcal/day) after a palm oil tax. To be conservative and follow the precautionary principle (providing an upper bound estimate for the adverse effects of a palm oil tax), we used the largest expenditure elasticity of food from the lowest income class in India $(0.65,95 \%$ confidence interval 0.41 to 0.89$),{ }^{38}$ as this group is at highest risk for food insecurity and is most sensitive to changes in food prices.

\section{Sensitivity analyses}

We did univariate sensitivity analyses in which each parameter was varied across the uncertainty range listed in the table $\Downarrow$ through deterministic simulations in which other parameters were held at their mean values, estimating the model's sensitivity to each parameter. This was followed by a multivariate uncertainty analysis in which the simulation was repeated 10 000 times by Monte Carlo sampling from the uncertainty ranges around each parameter in the table $\Downarrow$ and across the risk factor distributions listed in the appendix, generating $95 \%$ confidence intervals around the model's results. ${ }^{39}$ we used MATLAB version R2012a (MathWorks, Cambridge, MA) for all computations.

\section{Results}

\section{Projections of cardiovascular deaths}

Without any new interventions, the model based on trends in palm oil consumption (fig $1 \Downarrow$ ) projects that the 20 to 79 year old population of India will experience approximately 21.9 (95\% confidence interval 16.9 to 26.9 ) million deaths from myocardial infarctions and 14.7 (13.7 to 15.7) million deaths from ischemic stroke over the period 2014-23. A larger than average share of this burden would occur among men and among residents of cities, corresponding to risk factor rates and trends. About $16 \%$ of the population is accounted for by urban men, $35 \%$ by rural men, $15 \%$ by urban women, and $33 \%$ by rural women, but approximately $33 \%$ of the deaths from myocardial infarction would occur among urban men, followed by $31 \%$ among rural men, $19 \%$ among urban women, and $17 \%$ among rural women. About $27 \%$ of deaths from stroke would occur among urban men, 25\% among rural men, 25\% among urban women, and $23 \%$ among rural women.

A $20 \%$ palm oil tax without substitution with other oils would lower saturated fat intake per person in India by about 1.3 (95\% confidence interval 0.8 to 1.8$) \mathrm{g} /$ day and lower polyunsaturated fatty acid consumption by about $0.2(0.1$ to 0.3$) \mathrm{g} /$ day. The changes in consumption due to a $20 \%$ palm oil tax correspond to a decline in total cholesterol of about 0.08 (0.05 to 0.12$)$ $\mathrm{mmol} / \mathrm{L}$ : a $-1.7 \%(-1.0 \%$ to $-2.3 \%)$ change. A change of at least $0.009 \mathrm{mmol} / \mathrm{L}$ is considered clinically significant. ${ }^{40}$ The change in cholesterol from the palm oil tax would be expected to avert approximately 251000 (171000 to 331000$)$ deaths 
from myocardial infarction ( $1.4 \%(0.6 \%$ to $2.1 \%)$ of myocardial infarction deaths) and 112000 (76 000 to 148000 ) deaths from stroke $(0.8 \%$ ( $0.5 \%$ to $1.1 \%)$ of stroke deaths) over the 10 year period from 2014 to 2023 (figs $3 \Downarrow$ and $4 \Downarrow$ ).

When the substitutions of other major oils (mustardseed/rapeseed/groundnut) are taken into account, and a pessimistic substitution of palm oil with cottonseed oil in the smaller "other oils" category is included, saturated fat consumption would decline by about 1.1 (0.5 to 1.6) g/day, but polyunsaturated fats consumption would increase by about 0.30 ( 0.05 to 0.56$) \mathrm{g} /$ day owing to greater soybean oil consumption. This would correspond to a reduction in serum cholesterol of about 0.08 (0.05 to 0.12$) \mathrm{mmol} / \mathrm{L}(\mathrm{a}-1.7 \%(-1.1 \%$ to $-2.3 \%)$ change) and prevention of about 254000 (160 000 to 348000$)$ deaths from myocardial infarction (1.4\% (0.9\% to $1.9 \%$ of myocardial infarction deaths) and 113000 (71 000 to 155000$)$ deaths from stroke $(0.8 \%$ ( $0.5 \%$ to $1.1 \%)$ of stroke deaths).

When the substitutions of other major oils (mustardseed/rapeseed/groundnut) are taken into account, and an optimistic substitution of palm oil with soybean oil in the smaller "other oils" category is included, saturated fat consumption would decline by about 1.0 (0.4 to 1.6$) \mathrm{g} / \mathrm{day}$, but polyunsaturated fats consumption would increase by $0.80(0.55$ to 1.05$) \mathrm{g} /$ day owing to greater soybean oil consumption. This would correspond to a reduction in serum cholesterol of about $0.10(0.07$ to 0.13$) \mathrm{mmol} / \mathrm{L}$ (a $-2.0 \%(-1.3$ to $-2.6 \%)$ change $)$ and prevention of about 291000 (177000 to 405000$)$ deaths from myocardial infarction (1.6\% (1.0\% to $2.2 \%)$ of myocardial infarction deaths) and 130000 (79 000 to 181000$)$ deaths from stroke $(0.9 \%$ ( $0.6 \%$ to $1.3 \%)$ of stroke deaths).

The scenarios with and without substitution with other oils provide a lower and upper bound on estimates of the tax's potential effect on deaths, with the likely effect somewhere between these two extremes. Figure $4 \Downarrow$ shows the relative benefits among subpopulations; benefits would accrue more among urban populations and among older age groups than among rural and younger populations. Figure $4 \Downarrow$ also shows the difference in differences analysis, in which between group differences in mortality change (bottom panels).

\section{Potential adverse effects of palm oil tax}

A $20 \%$ palm oil tax along with substitution with other oils would be expected to result in a reduction of intake of 13.1 kilocalories per person per day in India and an increase in food insecurity by about $0.59 \%(0.50 \%$ to $0.68 \%)$, leading to new chronic food insecurity for 73000 (46 000 to 100000 ) Indians, after changes in household expenditure due to the tax and kilocalorie differences among oils have been accounted for. This relates to at most 16000 (12000 to 22000 ) deaths over 10 years on the basis of the highest relative risk estimates of all cause mortality attributable to food insecurity $(2.06,95 \%$ confidence interval 1.75 to 2.37 , versus non-insecure). ${ }^{41}$

\section{Sensitivity analyses}

A $10 \%$ tax instead of a $20 \%$ tax reduced efficacy by $50 \%$ in terms of averted deaths from myocardial infarction and stroke, whereas a $30 \%$ tax increased efficacy by $50 \%$ in terms of averted deaths. Among the various oils that may be substituted for palm oil, an increase in soybean oil consumption conferred the greatest benefit because it contains the highest quantity of polyunsaturated fat among the oils considered. A $1 \%$ rise in the consumption of soybean oil increased the number of averted deaths from myocardial infarctions and strokes by $0.5 \%$.

\section{Discussion}

In India, a $20 \%$ excise tax on palm oil for domestic consumption is projected to avert between 710000 and 930000 deaths from myocardial infarction and stroke (a 2-3\% reduction) over the period 2014-23, on the basis of nationally representative data describing key cardiovascular risk factors including blood pressure, cholesterol, diabetes, and tobacco smoking. This decline in cardiovascular deaths depends in part on how Indian consumers substitute other oils for palm oil. We found that should Indian consumers respond to rises in the price of palm oil by substituting with soybean oil, soybean's higher polyunsaturated fat content would be expected to provide further reductions in cardiovascular disease mortality. In terms of health equity, much of the decline in deaths is concentrated among men and urban dwellers, reflecting the heightened prevalence of major risk factors such as hypertension and hyperlipidemia among this group. This, combined with the worst case scenario of increased food insecurity, suggests that a palm oil tax may cause a net transfer of health from rural to urban populations and from women to men. Designing appropriate protections in existing food subsidy programs to accompany a palm oil tax therefore requires further consideration.

\section{Strengths and weaknesses of study}

Our model incorporates population representative data disaggregated by age, sex, and urban/rural residence; the different effects of a palm oil tax among groups in our results highlight the importance of a distributional aspect to fiscal policies affecting dietary choices, which have generally been projected on a whole country level rather than through disaggregated analyses.

These findings must, however, be contextualized by important limitations. Firstly, the analysis uses a mathematical model, which inherently cannot capture all aspects of reality or predict the future. Although the model matched independent disease estimates (appendix figures), its future projections rely on existing data and trends in prevalence of risk factors in the country, which may change through future health campaigns. Secondly, the model uses total cholesterol rather than a complete lipid profile to predict risk of cardiovascular disease, which has been validated in previous models. ${ }^{23}$ However, complex mechanistic understandings of low density lipoprotein profiles, high density lipoprotein profiles, and ultimate outcomes are not possible through this model, as nationally representative data on these cholesterol components are not available from India. Thirdly, we focused on palm oil taxation, but other types of fiscal policies are also increasingly being discussed in the literature, such as taxes on sugar sweetened beverages, which have not yet been modeled for India or most other low and middle income countries. Evidence on sugar sweetened beverage taxation has come mostly from Western countries to date and suggests that small taxes are likely to have an insufficient effect size to notably change outcomes when incorporating substitution patterns, but larger taxes in the order of $20-25 \%$ may be more effective. ${ }^{1542} 43$ Further data on consumption of other goods and fiscal approaches to affecting their use could provide opportunities for direct comparison between palm oil taxes and other strategies to identify the approaches with highest comparative effectiveness.

\section{Strengths and weaknesses in relation to other studies}

These results are consistent with the natural experiment in Mauritius, where saturated fat sources were replaced through 
government action by polyunsaturated fat sources. However, the effect sizes of the intervention in Mauritius were much larger, with a decline in mean cholesterol of about $0.7 \mathrm{mmol} / \mathrm{L}$ over five years at the same time that the fat replacement program was paralleled by other dietary changes; this decline is nearly 10-fold larger than the $0.08 \mathrm{mmol} / \mathrm{L}$ tax effect projected here, ${ }^{13}$ owing to the much smaller reduction in consumption achieved by taxation than by elimination of market availability of an item. This implies that how fiscal interventions in low and middle income countries affect nutrition needs place specific analyses, as dietary composition, market availability, and consumer behavior differ between countries.

Our analysis is also unique in that it incorporates direct estimates of substitution between products, whereas a recent meta-analysis found that typical food tax analyses make assumptions of either no substitution or arbitrary substitution levels. ${ }^{31}$ Some of the other potential strategies to reduce cardiovascular disease include decreasing dietary sodium intake, restricting tobacco use, and expanding drug use. Compared with these other interventions, the palm oil tax simulated here would have smaller effects on deaths from myocardial infarction and stroke than would dietary sodium reduction (which is projected to lower cardiovascular mortality by about $5 \%$ in India over the same time period as that simulated here), tobacco use restrictions ( $25 \%$ reduction), and increased use of aspirin, statins, and antihypertensives $(5 \%$ reduction in combination when considering typical rates of access and adherence in India). ${ }^{44}$ Compared with these other studies, palm oil taxation may have more profound indirect negative effects on food insecurity, especially among rural populations who would need to spend more income for cooking oils, although dietary sodium reduction also poses other risks such as iodine deficiency. Mitigation of such adverse food insecurity effects could include measures such as increasing the affordability of healthier oil alternatives.

\section{Meaning of study}

Our study provides the first analysis of how taxes to reduce palm oil consumption may affect population health in India. India is not only expected to face the greatest burden of cardiovascular disease mortality among low and middle income countries but is also considered a policy leader in the prevention of chronic disease among these countries. ${ }^{1}$ As this study highlights, the use of fiscal strategies to alter nutrition in low and middle income countries may be a powerful tool to improve cardiovascular health, but the differential benefits among various demographic groups may require careful application of blanket fiscal policies in highly heterogeneous countries and further comparative analyses to find those food products that may be most beneficial to health among an array of food product substitutes. The major obstacles to further evaluating fiscal policies such as taxation include political opposition from the food manufacturing industry, the desire to avoid taxation as a generally unpopular strategy to influence behavior, and the potentially regressive nature of food taxes. ${ }^{46}$ The opposition of the food industry to regulation has been discussed extensively elsewhere, although product reformulation has now been seen as an avenue to respond to increasing consumer demand for healthier foods. ${ }^{47}$ Evidence gathering on where and how such strategies have been successfully implemented would facilitate further understanding of how positive aspects of the policies may be enhanced while potential adverse effects are reduced. A particular concern with palm oils is that they are significantly cheaper than other oils, partly because their production and distribution relies on mechanisms that include low wage compensation and poorly regulated land use that has contributed to climate change. ${ }^{48}$ The incentive to continue manufacturing a cheaper oil that generates high demand in Asia has been an obstacle to further regulating palm oil production from both a health and a climate change perspective.

\section{Unanswered questions and future research}

Future research should include studies of the heterogeneous effect of taxes among different income groups, for which data are not yet available to do income stratified assessments. Emerging evidence suggests that some but not all cardiovascular risk factors are shifting towards lower income populations over time ${ }^{49}{ }^{50}$ Another topic for investigation is whether subsidies to support healthier food consumption in low and middle income countries may be as effective as or more effective than taxes, an area studied in high income countries. ${ }^{31}$ Manufacturers also use palm oil as an additive, and further investigation should describe manufacturers' responses to palm oil taxes (raising prices, substituting other oils, or both).

We thank Jack Farquhar and Brian Chen for their assistance and insights.

Contributors: SB and JDG-F conceived of the study and did the analysis with SV and SA. All authors contributed to the analysis of results and writing of the manuscript. SB is the guarantor.

Funding: This work was funded by the National Institute on Aging (K01 AG037593-02, JGF; P30 AG017253, SB), the Stanford Woods Institute for the Environment (JDG-F), and the International Development Research Centre of Canada (SB, DS, SE, SV). The funders had no role in the study design, analysis, interpretation, or decision to submit for publication.

Competing interests: All authors have completed the ICMJE uniform disclosure form at www.icmje.org/coi_disclosure.pdf and declare: support for the submitted work as detailed above; no financial relationships with any organizations that might have an interest in the submitted work in the previous three years; no other relationships or activities that could appear to have influenced the submitted work.

Ethics approval: Not needed.

Data sharing: No additional data available.

Declaration of transparency: The lead author affirms that this manuscript is an honest, accurate, and transparent account of the study being reported; that no important aspects of the study have been omitted; and that any discrepancies from the study as planned (and, if relevant, registered) have been explained.

Institute of Medicine. Promoting cardiovascular health in the developing world: a critical challenge to achieve global health. National Academy Press, 2010.

2 Alwan A. Global status report on noncommunicable diseases 2010. World Health Organization, 2011.

3 Pearson TA. Cardiovascular disease in developing countries: myths, realities, and opportunities. Cardiovasc Drugs Ther 1999;13:95-104.

4 Chen BK, Seligman B, Farquhar JW, Goldhaber-Fiebert JD. Multi-country analysis of palm oil consumption and cardiovascular disease mortality for countries at different stages of economic development: 1980-1997. Global Health 2011;7:1-10.

5 Mensink RP, Zock PL, Kester AD, Katan MB. Effects of dietary fatty acids and carbohydrates on the ratio of serum total to HDL cholesterol and on serum lipids and apolipoproteins: a meta-analysis of 60 controlled trials. Am J Clin Nutr 2003;77:1146-55.

6 Vega-Lopez S, Ausman LM, Jalbert SM, Erkkila AT, Lichtenstein AH. Palm and partially hydrogenated soybean oils adversely alter lipoprotein profiles compared with soybean and canola oils in moderately hyperlipidemic subjects. Am J Clin Nutr 2006;84:54-62.

7 Verschuren WM, Jacobs DR, Bloemberg BP, Kromhout D, Menotti A, Aravanis C, et al. Serum total cholesterol and long-term coronary heart disease mortality in different cultures: twenty-five-year follow-up of the Seven Countries Study. JAMA 1995:274:131-6.

8 Dohlman EN, Persaud SC, Landes R. India's edible oil sector: imports fill rising demand. US Department of Agriculture, Economic Research Service, 2003.

9 US Department of Agriculture. Production, supply, and distribution (PSD) online. US Department of Agriculture, Foreign Agricultural Service, 2013 (available at www.fas.usda. gov/psdonline/psdhome.aspx).

10 Haytowitz D, Lemar L, Pehrsson P, Exler J, Patterson K, Thomas R, et al. USDA national nutrient database for standard reference, release 24. 2011. ars. usda.gov/Services/docs. $\mathrm{htm}$ ?docid=22808.

11 Mozaffarian D, Micha R, Wallace S. Effects on coronary heart disease of increasing polyunsaturated fat in place of saturated fat: a systematic review and meta-analysis of randomized controlled trials. PLoS Med 2010;7:e1000252. 


\section{What is already known on this topic}

Palm oil is now the primary vegetable oil used in South Asia, as in many developing countries

Palm oil has a very high saturated fat content and has been significantly associated with increased mortality rates for myocardial infarction in low and middle income countries

This association remains even after adjustment for time trends, tobacco use, and other saturated fat sources

\section{What this study adds}

A mathematical model incorporating nationally representative data on cardiovascular disease risk factors, palm oil consumption, and substitution of palm oil with other oils was used to investigate the potential effect of an excise tax on palm oils in India

Although palm oil taxation may modestly reduce hyperlipidemia and cardiovascular mortality, men and urban populations may benefit more than women and rural populations

The rise in the price of palm oil may also reduce food security among some groups

12 Zatonski WA, Willett W. Changes in dietary fat and declining coronary heart disease in Poland: population based study. BMJ 2005;331:187-8

13 Uusitalo U, Feskens EJM, Tuomilehto J, Dowse G, Haw U, Fareed D, et al. Fall in total cholesterol concentration over five years in association with changes in fatty acid composition of cooking oil in Mauritius: cross sectional survey. BMJ 1996;313:1044-6.

14 Thow AM, Jan S, Leeder S, Swinburn B. The effect of fiscal policy on diet, obesity and chronic disease: a systematic review. Bull World Health Organ 2010:88:609-14.

15 Wang YC, Coxson P, Shen YM, Goldman L, Bibbins-Domingo K. A penny-per-ounce tax on sugar-sweetened beverages would cut health and cost burdens of diabetes. Health Affairs 2012;31:199-207.

16 Registrar General and Census Commissioner. Census of India. Ministry of Home Affairs, 2011.

17 World Health Organization. Study on Global AGEing and Adult Health (SAGE). WHO, 2011.

18 World Health Organization. WHO Global InfoBase. 2012. https://apps.who.int/infobase/

19 Tobacco Free Initiative. Global Adult Tobacco Survey (GATS) India report 2009-2010. World Health Organization, 2011.

20 Sadikot SM, Nigam A, Das S, Bajaj S, Zargar AH, Prasannakumar KM, et al. The burden of diabetes and impaired glucose tolerance in India using the WHO 1999 criteria: prevalence of diabetes in India study (PODIS). Diabetes Res Clin Pract 2004:66:301-7.

21 Danaei G, Finucane MM, Lu Y, Singh GM, Cowan MJ, Paciorek CJ, et al. National, regional, and global trends in fasting plasma glucose and diabetes prevalence since 1980 systematic analysis of health examination surveys and epidemiological studies with 370 country-years and 2.7 million participants. Lancet 2011;378:31-40.

22 Shah B, Kumar N, Menon G, Khurana S, Kumar H. Assessment of burden of non-communicable diseases. WHO India, 2010.

23 Lim SS, Gaziano TA, Gakidou E, Reddy KS, Farzadfar F, Lozano R, et al. Prevention of cardiovascular disease in high-risk individuals in low-income and middle-income countries: health effects and costs. Lancet 2007;370:2054-62.

24 Teo KK, Ounpuu S, Hawken S, Pandey MR, Valentin V, Hunt D, et al. Tobacco use and risk of myocardial infarction in 52 countries in the INTERHEART study: a case-control study. Lancet 2006;368:647-58

25 World Health Organization. Disease and injury country estimates. WHO, 2008.

26 Food and Agricultural Organization. FAOSTAT database. 2013. http://faostat.fao.org.

27 Keys A, Anderson T, Grande F. Serum cholesterol response to change in the diet. Metabolism 1965;14:776-87.

28 Cappuccio FP. Ethnicity and cardiovascular risk: variations in people of African ancestry and South Asian origin. J Hum Hypertens 1997:11:571-6.

29 Anderson KM, Odell PM, Wilson PW, Kannel WB. Cardiovascular disease risk profiles. Am Heart J 1991;121:293-8.

30 De Wreede LC, Fiocco M, Putter H. The mstate package for estimation and prediction in non-and semi-parametric multi-state and competing risks models. Comput Methods Programs Biomed 2010;99:261-74.

31 Eyles $\mathrm{H}$, Mhurchu $\mathrm{CN}$, Nghiem N, Blakely T. Food pricing strategies, population diets, and non-communicable disease: a systematic review of simulation studies. PLoS Med 2012;9:e1001353.

32 Banks J, Blundell R, Lewbel A. Quadratic Engel curves and consumer demand. Rev Econ Stat 1997;79:527-39.

33 Ministry of Statistics and Programme Implementation. National sample survey. Government of India, 2012 (available from http://mospi.nic.in/Mospi_New/site/home.aspx).

34 Welch M, Mohanty S, Pan S. India edible oil consumption: a censored incomplete demand approach. Journal of Agricultural and Applied Economics 2008;40:821-35.
35 Ebrahim S, Kinra S, Bowen L, Andersen E, Ben-Shlomo Y, Lyngdoh T, et al. The effect of rural-to-urban migration on obesity and diabetes in India: a cross-sectional study. PLOS Med 2010;7:e1000268.

36 Narasinga Rao BS, Deosthale YG, Pant KC. Nutritive value of Indian foods. Indian Council of Medical Research, National Institute of Nutrition, 1989 .

37 Patel G. Consumer trends in India with reference to palm oil. Patel and Nikhil Research, 2011.

38 Kumar P, Kumar A, Parappurathu S, Raju S. Estimation of demand elasticity for food commodities in India. Agricultural Economics Research Review 2011;24:1-14.

39 Kuntz K, Weinstein M. Modelling in economic evaluation. In: Economic evaluation in health care: merging theory with practice. Oxford University Press, 2001.

40 Grundy SM, Cleeman JI, Merz CNB, Brewer HB, Clark LT, Hunninghake DB, et al. Implications of recent clinical trials for the national cholesterol education program adult treatment panel III guidelines. J Am Coll Cardiol 2004:44:720-32.

41 Young $\mathrm{H}$, Jaspars S. Review of nutrition and mortality indicators for the Integrated Food Security Phase Classification (IPC). United Nations Standing Committee on Nutrition, 2009.

42 Sturm R, Powell LM, Chriqui JF, Chaloupka FJ. Soda taxes, soft drink consumption, and children's body mass index. Health Aff (Millwood) 2010;29:1052-8.

43 Fletcher JM, Frisvold DE, Tefft N. Are soft drink taxes an effective mechanism for reducing obesity? J Policy Anal Manage 2011;30:655-62.

44 Basu S, Stuckler D, Vellakkal S, Ebrahim S. Dietary salt reduction and cardiovascular disease rates in India: a mathematical model. PloS One 2012;7:e44037.

45 Basu S, Glantz S, Bitton A, Millett C. The effect of tobacco control measures during a period of rising cardiovascular disease risk in India: a mathematical model of myocardial infarction and stroke. PLOS Med 2013;10:e1001480.

46 Brownell KD, Farley T, Willett WC, Popkin BM, Chaloupka FJ, Thompson JW, et al. The public health and economic benefits of taxing sugar-sweetened beverages. N Engl J Med 2009;361:1599-605.

47 Stuckler D, McKee M, Ebrahim S, Basu S. Manufacturing epidemics: the role of global producers in increased consumption of unhealthy commodities including processed foods, alcohol, and tobacco. PLoS Med 2012;9:e1001235.

48 Carlson KM, Curran LM, Asner GP, Pittman AM, Trigg SN, Adeney JM. Carbon emissions from forest conversion by Kalimantan oil palm plantations. Nat Clim Chang 2012;3:283-7.

49 Sullivan R, Kinra S, Ekelund U, Bharathi AV, Vaz M, Kurpad A, et al. Socio-demographic patterning of physical activity across migrant groups in India: results from the Indian Migration Study. PLoS One 2011;6:e24898.

50 Sovio U, Giambartolomei C, Kinra S, Bowen L, Dudbridge F, Nitsch D, et al. Early and current socio-economic position and cardiometabolic risk factors in the Indian Migration Study. Eur J Prev Cardiol 2013;20:844-53.

\section{Accepted: 17 September 2013}

\section{Cite this as: BMJ 2013;347:f6048}

This is an Open Access article distributed in accordance with the Creative Commons Attribution Non Commercial (CC BY-NC 3.0) license, which permits others to distribute, remix, adapt, build upon this work non-commercially, and license their derivative works on different terms, provided the original work is properly cited and the use is non-commercial. See: http://creativecommons.org/licenses/by-nc/3.0/. 


\section{Table}

\section{Table 1| Model parameters and data sources}

\begin{tabular}{|c|c|c|}
\hline Parameters & Values $(95 \% \mathrm{Cl})$ & Data sources \\
\hline Population size and demographic trends & Stratified by age, sex, and urban/rural residence & Census of India, $2011^{16}$ \\
\hline Population distribution of systolic blood pressure & Appendix tables 1 and 8 & World Health Organization estimates, $2011^{17}$ \\
\hline Population distribution of total cholesterol & Appendix tables 2 and 8 & World Health Organization estimates, $2012^{18}$ \\
\hline Population distribution of tobacco smoking & Appendix tables 3 and 8 & Global Adult Tobacco Survey, 2009-10 ${ }^{19}$ \\
\hline Prevalence of diabetes & Appendix tables 4 and 8 & $\begin{array}{l}\text { Cross sectional survey, } 2004 \text {, updated using estimates } \\
\text { from Bayesian analysis of prevalence trends, } 2011^{20,21}\end{array}$ \\
\hline Prevalence of coronary heart disease & Appendix table 5 and 8 & World Health Organization estimates, $2010^{22}$ \\
\hline Prevalence of cerebrovascular disease & Appendix tables 6 and 8 & World Health Organization estimates, $2010^{22}$ \\
\hline Correlation among risk factors listed above & Appendix table 7 & Institute for Health Metrics and Evaluation, $2007^{23}$ \\
\hline $\begin{array}{l}\text { Relative risk of coronary heart disease and } \\
\text { cerebrovascular disease conferred by changes in } \\
\text { each risk factor listed above }\end{array}$ & Appendix table 9 & Previous reviews of international datasets ${ }^{23,24}$ \\
\hline $\begin{array}{l}\text { Mortality rates from coronary heart disease, } \\
\text { cerebrovascular disease, and other causes }\end{array}$ & Appendix tables 10 and 11 & World Health Organization estimates, $2008^{25}$ \\
\hline Own price elasticity of palm oil & $-0.71(95 \% \mathrm{Cl}-0.44$ to -0.98$)$ & $\begin{array}{l}\text { Quadratic Almost Ideal Demand System estimate from } \\
\text { Indian National Sample Survey (nationally representative } \\
\text { household survey) }\end{array}$ \\
\hline Cross price elasticities for other oils & $\begin{array}{l}\text { Rapeseed/mustard seed oil: } 0.70 \text { ( } 0.27 \text { to } 1.12) \text {; } \\
\text { groundnut } 0.67 \text { ( } 0.38 \text { to } 1.19) \text {; coconut oil: } \\
\text { non-significant; soybean, cottonseed, and sunflower } \\
\text { oils varied in simulations: in pessimistic scenario, all } \\
\text { deferred palm oil expenditure goes to cottonseed; in } \\
\text { optimistic scenario, all deferred expenditure goes to } \\
\text { soybean oil }\end{array}$ & $\begin{array}{l}\text { Quadratic Almost Ideal Demand System estimate from } \\
\text { Indian National Sample Survey }\end{array}$ \\
\hline Saturated fat content per $100 \mathrm{~g}$ oil & $\begin{array}{l}\text { Palm: } 49.3 \text { g; soy: } 15.7 \text { g; cottonseed: } 25.9 \mathrm{~g} \text {; } \\
\text { sunflowerseed: } 10.8 \mathrm{~g} \text {; rape/mustardseed: } 9.5 \mathrm{~g} \text {; } \\
\text { groundnut: } 16.9 \mathrm{~g} \text {; coconut: } 86.5 \mathrm{~g}\end{array}$ & United States Department of Agriculture ${ }^{10}$ \\
\hline Polyunsaturated fat content per $100 \mathrm{~g}$ oil & $\begin{array}{l}\text { Palm: } 9.3 \mathrm{~g} \text {; soy: } 57.7 \mathrm{~g} \text {; cottonseed: } 51.9 \mathrm{~g} \text {; } \\
\text { sunflowerseed: } 36.5 \mathrm{~g} \text {; rapeseed/mustardseed: } 24.6 \\
\text { g; groundnut: } 32.0 \mathrm{~g} \text {; coconut: } 1.8 \mathrm{~g}\end{array}$ & United States Department of Agriculture ${ }^{10}$ \\
\hline Threshold for food insecurity & $1780 \mathrm{kcal} / \mathrm{day}$ & United Nations Food and Agriculture Organization ${ }^{26}$ \\
\hline $\begin{array}{l}\text { Current distribution of kilocalorie consumption in } \\
\text { India }\end{array}$ & Mean 2323 (SD 581) & United Nations Food and Agriculture Organization ${ }^{26}$ \\
\hline $\begin{array}{l}\text { Income elasticity for food, lowest income sector } \\
\text { (<75\% of poverty level) }\end{array}$ & Mean 0.65 (SD 0.12) & $\begin{array}{l}\text { Quadratic Almost Ideal Demand System model of data } \\
\text { from Indian National Sample Survey }\end{array}$ \\
\hline
\end{tabular}

Complete data values are provided in appendix tables, as listed. 


\section{Figures}

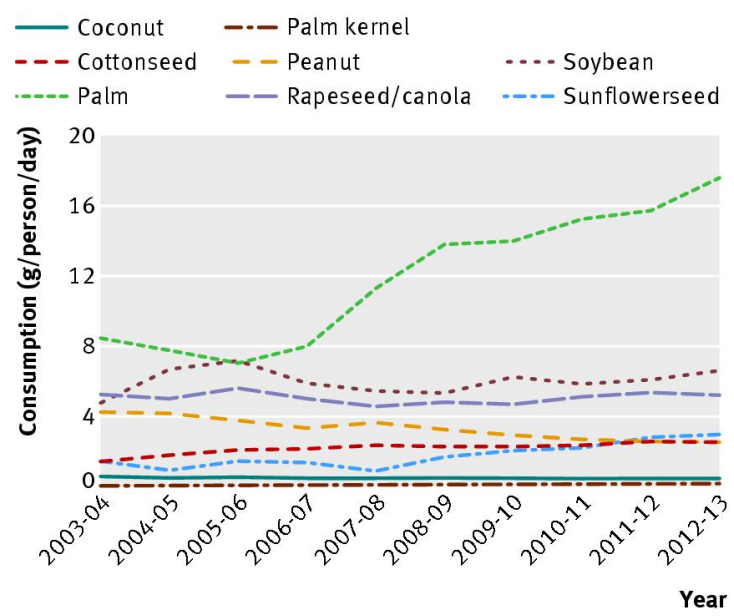

Fig 1 Change in domestic food consumption of major vegetable oils in India, 2003-12. ${ }^{9}$ All other oils are of lower per capita consumption than those shown

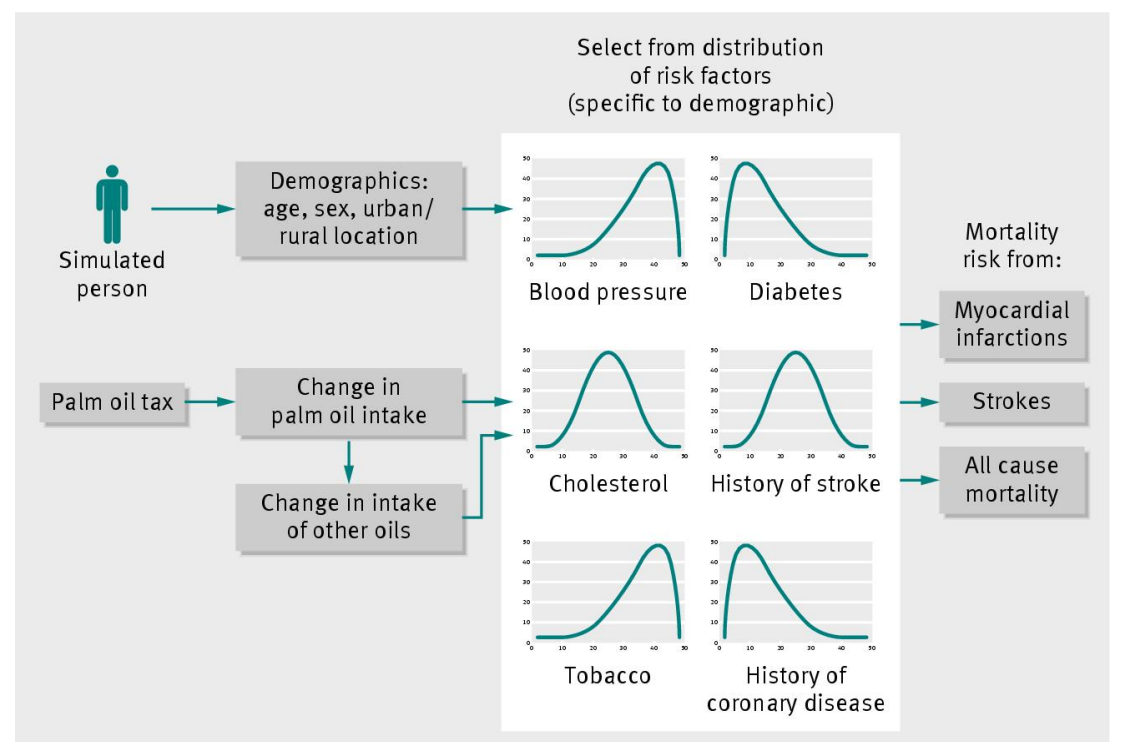

Fig 2 Activity diagram for microsimulation model. 10000 people are simulated from each of 24 cohorts defined by 10 year age groups (20-29, 30-39, .., 70-79 years), sex, and rural versus urban location. Each simulated person is assigned a cardiovascular disease "risk factor profile" based on cohort specific data on six risk factors: systolic blood pressure, total cholesterol, tobacco smoking, diabetes, coronary heart disease, and cerebrovascular disease. Cardiovascular disease mortality from myocardial infarctions and strokes (using a Framingham-like risk equation), as well as all cause mortality, are calculated. Palm oil taxation is simulated by calculating how changes in palm oil consumption (and potential substitution with other oils) affect total cholesterol 



Fig 3 Daily saturated and polyunsaturated fat intake from vegetable oils among 20-79 year old adults in India, before and after $20 \%$ palm oil tax. "No substitution" refers to scenario in which $20 \%$ palm oil tax results only in reduction in palm oil consumption but no substitution with other oils. "Pessimistic substitution" refers to pessimistic scenario in which some palm oil consumption is substituted with major oils (rapeseed, mustard seed, and groundnut) in proportion to their cross elasticities, and proportion of oil substituted from "other oils" category in Indian National Sample Survey (in addition to major oils) goes toward cottonseed oil (least healthy "other oil" in terms of saturated fat per gram). "Optimistic substitution" refers to optimistic case in which "other oil" substitution goes toward soybean oil (most healthy product in "other oil" category). On each box, central mark is median, edges of box are 25th and 75th centiles, and whiskers extend to 1.5 times interquartile range (capturing $99.3 \%$ of distribution)
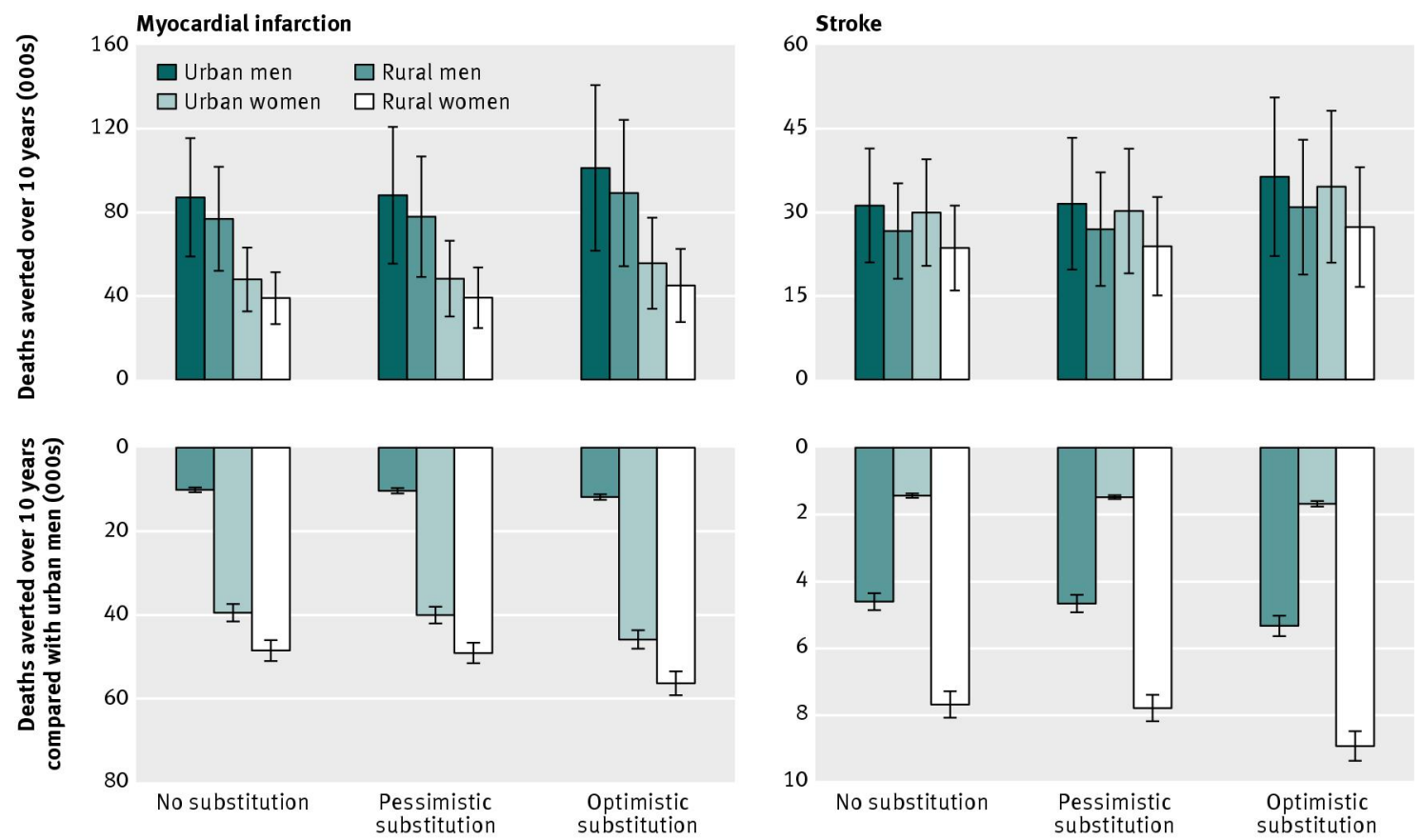

Fig 4 Estimated future mortality averted from myocardial infarctions and strokes among 20-79 year old adults in India (top). See fig $3 \Downarrow$ for explanation of substitution scenarios. Wide confidence intervals are due more to uncertainty in baseline risk estimates than to uncertainty between simulated tax scenarios; to illustrate this, between group differences in change in mortality from myocardial infarctions and strokes relative to urban men group within each of 10000 simulations are shown (difference in differences chart) (bottom) 